\title{
A Numerical Analysis on the Wind-Resistance Strengthening with Guy Wires for Distribution Lines
}

\author{
Yi-feng $\mathrm{He}^{1}$, Yi Huang ${ }^{2 *}$, Jian-long $\mathrm{Cai}^{3}$ and Zhuo-feng Chen ${ }^{2}$
}

1. Huizhou Power Supply Bureau, Guangdong Power Grid Co., Ltd, Huizhou 516001, China;

2. Guangzhou Power Electric Technology Co., Ltd, Guangzhou 510640, China;

3. Huizhou Electric Power Design Institute, Huizhou 516001, China

\begin{abstract}
Keywords: Distribution Line, Guy Wire, Wind-Resistance Strengthening, Single Circuit.
\end{abstract}
\begin{abstract}
Installing guy wire is an effective strengthening method to improve the wind resistance of distribution power lines. A numerical study on the guy-wire-strengthened method to $10 \mathrm{kV}$ distribution lines with finite element method (FEM) is presented in this paper. Firstly, a 3D FEM model of a standard section of $10 \mathrm{kV}$ distribution line with single circuit is created by finite element analysis software, ABAQUS/CAE. The proposed model includes the components, lines, poles, cross arms, and guy wires. The wind loading acting at the poles and lines can be applied by equivalent gravitational acceleration. Then the deflection of the pole under specific wind speed is analyzed. The strengthening effect of the installation position and angle of guy wire on the distribution lines is discussed finally. The research results may provide theoretical reference on the wind-resistance strengthening design of the structures.
\end{abstract}

\section{Introduction}

Violent typhoon attacks the coast areas at South China every year, and destroys the overhead lines in varying degrees [1]. 10kV distribution line subjected to the most serious damage because its low design level of wind-resistance, aging and maintenance shortage. For the sake of reinforcing the distribution line, Ref. [2] proposed a series of strengthening measures, including foundation underpinning, using high strength poles, installing guy wire, decreasing the length of a strain section, et al. Installing guy wire is a common strengthening method because of its working convenience, lower cost and better effectiveness. But the paper didn't present the operational approach. Power grid company authorized a standard on wind-resistance reinforcement of distribution lines [3]. The design standard and reinforcing guideline don't provide detailed description, which caused some strengthened poles broken by typhoon. So, it is important to study the guy wire strengthening method.

The finite element method is an effective numerical method to analyze the mechanics problem of grid lines. Lou, et al. studied the dynamic wind deflection response of $500 \mathrm{kV}$ strain section with eight spans with FEM and harmony superposition method [4]. He, et al. established a tower-line coupled element model by using ANSYS, and analyzed the static response under different wind directions [5]. Zhou, et al. built real size tower-line system by using ABAQUS to simulate the waving of six split conductors [6]. The above researches focused on the numerical analysis of tower and wires by using finite element software, and the anti-wind capability, inner force and deflection of poles of the enhanced system hadn't be studied. This paper investigates the reinforcement effect of $10 \mathrm{kV}$ single circuit line with guy wires by ABAQUS, including the impact of installing position and angle of guy wires.

\section{Finite Element Model}

\section{Overhead Line}

Base on a standard section of $10 \mathrm{kV}$ single circuit overhead line, a pole-wire coupling model is established, shown as Fig.1. The components including: wire, RC pole, cross arm and guy wire. The elements selection and division are shown in Table 1. 


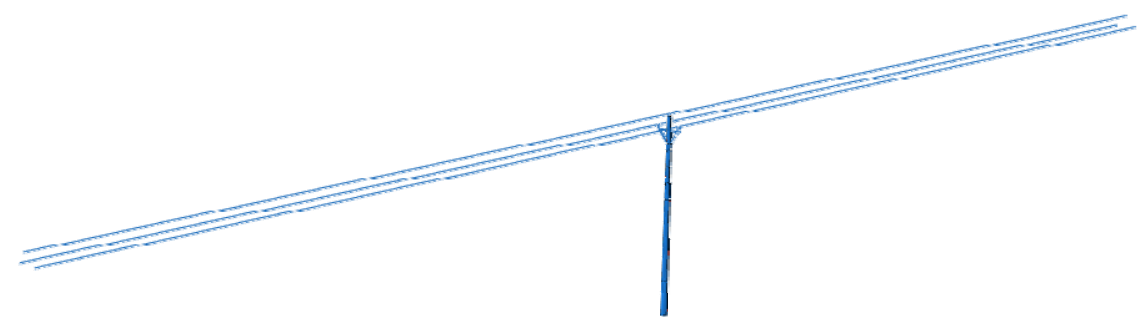

Fig.1 Finite element model

Table 1 Elements selection and division

\begin{tabular}{|c|c|c|c|c|c|}
\hline Component & Concrete & Steel & Cross arm & Wire & Guy wire \\
\hline Element type & C3D8R & T3D2 & B32 & T3D2 & T3D2 \\
\hline Element amount & 5760 & 382 & 200 & 1202 & - \\
\hline
\end{tabular}

\section{Size and Parameter}

The RC pole discussed in this paper is a M Grade high strength pole, whose size is: height $12 \mathrm{~m}$, base diameter $350 \mathrm{~mm}$, top diameter $190 \mathrm{~mm}$, wall thickness $60 \mathrm{~mm}$, and burial depth $2 \mathrm{~m}$. The concrete grade is C60. In the concrete, arranges $19 \emptyset 9$ High-tensile wires, with standard value of strength $1470 \mathrm{MPa}$, tensile strength $1040 \mathrm{MPa}$, compressive strength $410 \mathrm{MPa}$, and elasticity modulus 205GPa. The wire's type is JL/GIA-150/20, diameter $16.67 \mathrm{~mm}$, cross sectional area $164.5 \mathrm{~mm} 2$, equivalent density $3339.8 \mathrm{~kg} / \mathrm{m} 3$, integrated elastic coefficient $73 \mathrm{GPa}$, intensity strength of conversion $283.5 \mathrm{MPa}$. The span of the circuit is $60 \mathrm{~m}$. The cross arm uses Steel Q345, type $\angle 75$ $\times 6$. Diagonal bracing uses Steel Q235, type $\angle 50 \times 50$, elasticity modulus $201 \mathrm{GPa}$. The guy wire is Steel Strain GJ50, which is advised by South China Grid's typical design guide.

\section{Loading Simulation}

The loading includes gravity loads and wind loads. The gravity loads, cover the wires, cross arms and $\mathrm{RC}$ pole, can be subjected by gravitational acceleration. The considered wind loads are that applied on the wires and the pole. In the element model, the wind loads should be subjected by transformed into equivalent inertial acceleration.

\section{Effect of the Enhancing Position}

Installing position and angle of guy wires should influence the reinforcement effect. Firstly, let's consider the effect of the enhanced position. Let the guy wire joints the pole with angle $30^{\circ}$ by a hoop, whose size is same to the diameter of pole section. The bottom of the guy wire set as hinge joint. A wind speed $45 \mathrm{~m} / \mathrm{s}$ is applied to the model as wind loading.

The guy wire may be installed in six positions, shown in Fig.2(a). The length of the guy wire, L1 and L2, can be found by geometrical relationship. Fig.2(b) shows the pole's deflection corresponding to different enhancing position. It can be found that, comparing with the unstrengthened pole, the deflection of the strengthened pole decreases sharply. Especially, at the position 1, 2 and 3, the deflections of the top pole are very small. It has the best reinforcement effect. When the position move down (position 4, 5 and 6), the deformation increasing. It shows that the strengthening work not good.

From the above study, it can be conclued that, under a certain wind loading, the pole deforms more when the guy wire installed close to the ground. It is of disadvantage of promoting the wind resistance ability. In some failed engineering, operators installed the guy wire at the middle of the poles and caused the pole broken near the hoop. So, installing the guy wire near the diagonal bracing hoop would obtain the best reinforcement effect. 


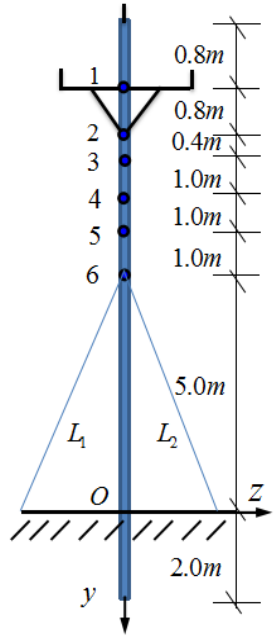

(a) Installing position

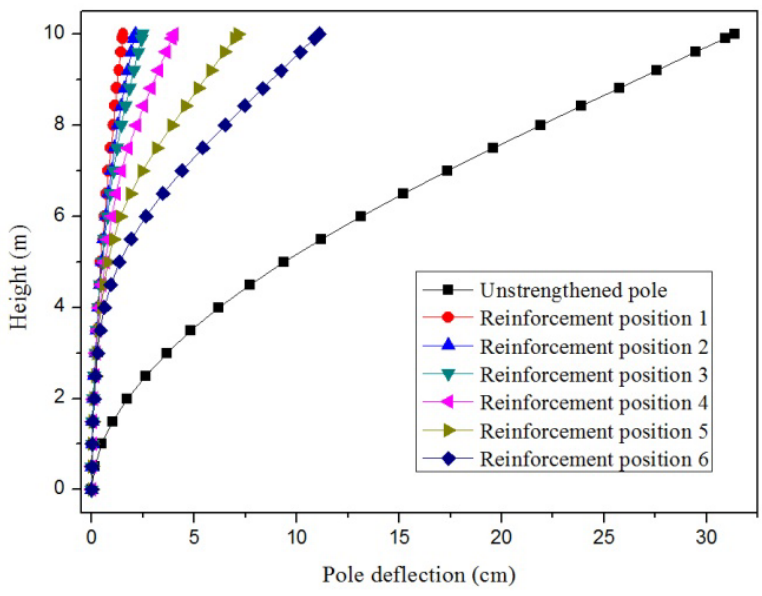

(b) Pole's deflection

Fig. 2 The installing position of guy wire and the pole deflection

\section{Effect of the Enhancing Angle}

The enhancing angle of guy wire also have contributed to the reinforcement effect. Fig.3(a) shows the model for investigating the effect of installing angle to the reinforcement. Base on the results of section 2, the guy wire should use a same hoop with the diagonal bracing and installed at Section A, where is $1.6 \mathrm{~m}$ to the top. The lengths of the wires are L1 and L2 respectively. $\alpha$ is the installing angle of guy wires, and changes from $25^{\circ}$ to $50^{\circ}$.

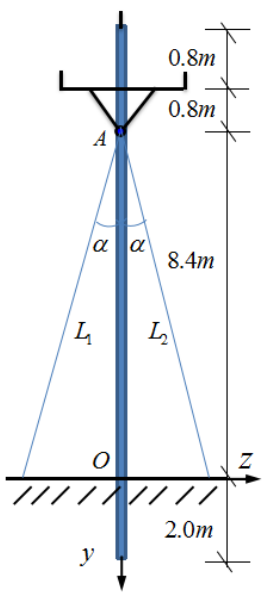

(a) Installing angle

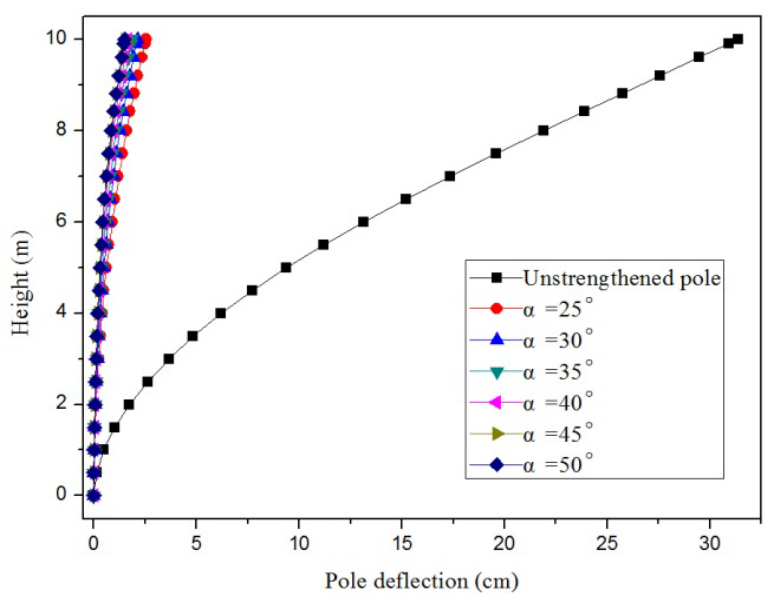

(b) Pole's deflection

Fig.3 The installing angle of guy wire and the pole deflection

The calculation result of deflections of the pole is shown in Fig.3(b). Comparing with the unstrengthened pole, the strength one has less deformation. It will increase when the enhancing angle decrease. But the change is very small. So, the enhancing angle has limit effect on the pole.

From the above study, it can be known that, when the enhancing angle changes, the pole doesn't deform obviously. If the guy wire has been installed at a correct position, the wind resistant capability can be promoted satisfactorily despite the different enhancing angle. At the other hand, small angle may enlarge the wire's tensile force. It means that under construction, the higher uplift bearing capability of pull plate and higher specification of guy wire should be considered. 


\section{Conclusions}

The reinforcement effect of installing guy wire to $10 \mathrm{kV}$ single circuit line is studied by numerical method. A space coupling wire-pole finite element model of a standard section of distribution line is established to investigate the strengthening effect of guy wire installing position and angle. The research results show that the guy wire should be installed at the hoop of diagonal bracing, and has less relevance to the installing angle.

\section{References}

[1] Feng Wang, Lijuan Li, Canbing Li, et al. Procedure and Model of Antidisaster Differentiated Planning for a Power Distribution System[J]. ASCE, Journal of Energy Engineering, 2016, 142(1): $1-8$.

[2] Chen Yongqiu, NongShaoan, Yang Xi, et al. Discussions on technical measures taken for windproof strengthening low-voltage overhead lines in coastal areas [J]. Power System and Clean Energy, 2014, 30(5): 61-65. (in Chinese)

[3] Standard technology on windproof design of distribution lines [S]. China Southern Power Grid, 2013. (in Chinese)

[4] Lou Wenjuan, Yang Yue, Lu Ming, et al. Conductor swinging dynamic characteristic and calculation model of continuous multi-span transmission line [J]. Electric Power Construction, 2015, 36(2): 1-8. (in Chinese)

[5] He Bo, XiuYaping, Zhao Heng, et al. Simulation analysis of mechanical behavior of high voltage tower-line coupled system under strong typhoons Part I: static response analysis [J]. High Voltage Apparatus, 2016, 52(4): 36-41. (in Chinese)

[6] Zhou Linshu, Yan Bo, Yang Xiaohui, et al. Galloping simulation of six-bundle conductors in a transmission test line [J]. Journal of Vibration and Shock, 2014, 33(9): 6-11. (in Chinese) 